\title{
O CONTRATO COMO OPERAÇÃO ECONÔMICA: CONTRIBUTO CIENTÍFICO A PARTIR DA OBRA DE ENZO ROPPO
}

\author{
THE CONTRACT AS ECONOMIC OPERATION: \\ CONTRIBUTION FROM THE SCIENTIFIC WORK OF ENZO ROPPO
}

Ivan Guimarães Pompeu ${ }^{1}$
Renata Guimarães Pompeu

\section{Resumo}

O presente trabalho tem como tema central a articulação existente entre a realidade jurídica representada pelo contrato e a operação econômica que ele legitima. O propósito aqui reside em tornar mais consistente o estudo jurídico do contrato por meio do reconhecimento e da compreensão do fato sócio-econômico que o constitui.

Palavras-chave: contrato, autonomia privada, direito, economia.

\section{INTRODUÇÃO}

A motivação jurídica ou a hipótese metodológica que mobilizou a redação do presente texto reside na articulação inseparável entre os contratos e a Economia ${ }^{3}$. O contrato como operação de natureza multidisciplinar se projeta em espaços como o Direito, a Economia, a Sociologia e a Hermenêutica. O tema aqui investigado refere-se ao contrato em sua acepção jurídica como instrumento organizador e legitimador da operação econômica. Considerar ou estudar o instituto contratual sem o obrigatório viés econômico que lhe é próprio representaria descompromisso científico. O estudo do contrato à luz da Análise Econômica do Direito ${ }^{4}$ significa trazer ao debate mais uma, dentre tantas, ferramentas hermenêuticas ${ }^{5}$.

1 Especialista em Direito de Empresa CAD/Gama Filho. Mestre em Direito Privado pela PUC/MG. Professor do curso de Direito da FEAD e PUC/MG. Membro da Associação Mineira de Direito e Economia. Advogado.

2 Especialista em Processo Civil CAD/Gama Filho. Mestre em Direito Civil pela UFMG. Doutoranda em Direito Privado pela PUC/MG. Professora do curso de Direito do Centro Universitário Newton Paiva. Membro da Associação Mineira de Direito e Economia. Bolsista da CAPES.

3 Neste mesmo sentido Vicenzo Roppo: "L’área del contratto è, in parole più empiriche, l'area degli impegni economici concordati e legalmente vincolanti (cioè coercibili coi mezzi della legge): àrea strategica in ogni organizzazione sociale, e segnatamente neele società evolute". (ROPPO, 2001, p. 3). Igualmente registrou Fernando Araújo: “(...) na visão mais ampla que é consentida pelo prisma económico, o contrato é essencialmente um facilitador da circulação de titularidades de valores e de modos de governo conjunto (ou governação) de problemas atinentes ao conhecimento, ao poder e aos interesses”. (ARAÚJO, 2007, p. 18).

4 Por certo o Direito representa uma ciência autônoma, mas conta também com um contexto de interdisciplinaridade que não pode ser negado. Economia e Direito articulados em nada se afastam dos seus fundamentos nucleares, apenas possibilitam (aqui para o Direito) uma análise mais consistente das inúmeras realidades às quais se deve oferecer tratamento ou regulação.

5 “A análise econômica do contrato pretende ser complementar da análise jurídica (...) fazendo recair uma especial atenção nos efeitos geradores de riqueza que podem associar-se àquele acordo de coordenação de condutas, efeitos que o transformam em veículo de consumação e permuta de utilidades". (ARAÚJO, 2007, p. 14)

Revista da Faculdade Mineira de Direito, v.12, n. 23, jan./jun. 2011 - ISSN 1808-9429. 
O que se quer dar ênfase aqui é que a noção de contrato como realidade jurídica deve sempre considerar a operação econômica ${ }^{6}$ que lhe subjaz, pois assim tornará consistente o arcabouço legal do direito dos contratos. O contrato como operação econômica foi investigado por Enzo Roppo em sua clássica obra O Contrato (2009), e também abordada na obra de título idêntico, mas escrita sob o nome de Vicenzo Roppo, Il Contratto (2001).

O propósito é recuperar algumas das reflexões de natureza econômica feitas pelo autor italiano articulando-as ou reinterpretando-as sob a ótica dos conceitos fundamentais da Análise Econômica do Direito, tais como riqueza, eficiência, agente racional ${ }^{7}$, custos de transação ${ }^{8}$, mercado, simetria e assimetria de informações, externalização sobre terceiros, dentre outros.

Neste caminho sugere-se como recurso conceitual esclarecedor a concepção de empresa firmada por Ronald Coase ${ }^{9}$ como um complexo ou "feixe" de contratos cujos custos de transação são extremamente relevantes. A empresa representaria um contexto dinâmico de atividades, relações e transações econômicas, traduzidas juridicamente pela figura do contrato. A natureza contratual da empresa é trazida aqui, pois auxilia a reflexão sobre o ajuste contratual de condutas. Ela ilustra um contexto de evidente e natural consideração dos aspectos econômicos, presentes nas relações jurídicas ditas contratuais.

O contrato como realidade jurídica que é, representa, em linhas gerais, um acordo ou ajuste de condutas, legitimado pelas diretrizes que emanam do princípio da autonomia negocial. Ser autônomo no âmbito do Direito Privado pressupõe a titularidade de um poder jurídico de se auto-regular, denominado autonomia privada. Mas, nem todos os espaços do Direito Privado permitem o pleno exercício desta autonomia, pois neles se impõe o heterônomo comando legal, cuja natureza é essencialmente coerciva.

O contrato como fato jurídico revela natureza complexa que se inicia por legitimar um fato social de conteúdo patrimonial (sendo um dos seus principais elementos a articulação

6 "De facto, falar em contrato significa sempre remeter - explícita ou implicitamente, directa ou mediatamente para a idéia de operação económica". (ROPPO, 1998, p. 8).

7 "Uma persona razonable está socializada conforme a las normas y convenciones de uma comunidad. De tal suerte que sus fines son congruentes com los valores compartidos, y su busqueda de ellos se corresponde com las normas del grupo." (COOTER y ULLEN, 2008).

8 Nas palavras de Fernando Araújo, Ronald Coase teria recuperado o conceito de custo de transação articulando: “(...) a comparação de eficiências entre a solução de mercado e a solução de integração numa empresa como formas de arregimentação e organização dos fatores produtivos - ou seja, a solução horizontal de compra no mercado confrontada com a solução de coordenação vertical da produção através de factores subordinados a uma organização hierárquica." (ARAUJO, 2007, p. 198).

9 In my article on "The Nature of the Firm" I argued that, although production could be carried out in a completely decentralized way by means of contracts between individuals, the fact that it costs means something to enter into these transactions means that firms will emerge to organize what would otherwise be market". (COASE, 1988, p. 7). 
econômica), compondo, em seguida, uma realidade técnica (caminhando pelos planos da validade e eficácia), cujas normas jurídicas que o regulam surgem das regras e princípios legais. (ROPPO, 2009). E todas estas realidades ocorrem ao mesmo tempo, simultânea e sequencialmente.

Subjacente a este conceito técnico de contrato mencionou-se a presença da operação econômica em que se dá a articulação de interesses entre particulares. $\mathrm{O}$ que se troca por meio da transação apresenta sempre uma natureza patrimonialmente apreciável. Porém, o processo dessa operação econômica conta igualmente com preocupações ou expectativas de ordem existencial. A formação do vinculo, seja ainda em nível anterior ao mundo jurídico, como fato social, pressupõe uma rede de pretensões imaginadas pelos agentes para realizarem as trocas.

A Análise Econômica do Direito considera que os agentes que se articulam agem de forma racional, delineando atuações consistentes como recurso para a maximização de seus interesses. A reflexão que se propõe reside na noção de maximizar auto-interesse no universo capitalista. Pretende-se esclarecer que a conduta que promove interesse próprio nem sempre recusa, rejeita ou prejudica interesse comum, bem como a conduta que afirma considerar o bem-estar social nem sempre auxilia no desenvolvimento de todos. E o contrato por possibilitar uma evidente circulação de riquezas pode, deve e existe para articular o cenário público e o privado.

A operação econômica recebida no plano da existência do mundo jurídico ilustraria, assim, as escolhas racionais (COOTER y ULEN, 2000) ou a disposição negocial de cada parte, as quais apresentam interesses contrapostos, mas ajustáveis. No processo de negociação os participantes considerarão o que já se mencionou como custo de transação. Além das expectativas existenciais propriamente ditas, o contrato pressupõe também uma contabilidade de custos de maneira a gerar uma escolha consistentemente articulada.

Considera-se que o processo negocial dos contratos sempre deverá articular fatores de heteronomia (condutas realizadas por dever/necessidade) e de autonomia (condutas movidas por vontade). O contrato organiza tecnicamente, ou legitima a operação econômica que é constituída por um sistema de trocas em que cada parte é influenciada por variáveis múltiplas (aqui denominadas custos de transação) para que se produza a escolha possível, pressupostamente consistente.

\section{DISPOSIÇÕES GERAIS SOBRE O CONTRATO}

A disciplina jurídica dos contratos segue como orientação básica todas as normas legais relativas ao negócio jurídico e neste contexto destaca-se, na essência, o poder negocial 
e a composição das categorias jurídicas. O contrato tem seu relevo como negócio jurídico que é por meio do exercício da autonomia privada para possibilitar a composição do conteúdo que se pretende na relação negocial.

Entretanto além do destaque dado à autonomia contratual e sua possibilidade de exercício entre o campo da heteronomia, o contrato também apresenta uma estrutura jurídica clássica que o define como negócio jurídico bilateral para permitir a criação, modificação, extinção e manutenção de direitos e obrigações cuja natureza patrimonial é predominante.

\begin{abstract}
Até aqui procedemos à identificação de uma sequência, uma articulação de termos, na qual parece oportuno decompor o conceito de que nos ocupamos: operação econômica - contrato - direito dos contratos. Quer dizer: a operação econômica, na sua materialidade, como substracto real necessário e imprescindível daquele conceito; o contrato como formalização jurídica daquela, isto é como conquista da idéia de que as operações econômicas podem e devem ser reguladas pelo direito, e como construção da categoria científica idônea para tal fim; o direito dos contratos, como conjunto - historicamente mutável - das regras e dos princípios, de vez em quando escolhidos para conformar, duma certa maneira, aquele instituto jurídico, e, portanto, para dar um certo arranjo - funcionalizado a determinados fins e a determinados interesses - ao complexo das operações econômicas efectivamente levadas a cabo. (ROPPO, 2009, p. 11)
\end{abstract}

Para que se discuta então o contrato como operação econômica é necessário o retorno à definição de sua estrutura jurídica clássica, porém apresentando renovada percepção do fenômeno da autonomia privada que deve ser compreendida entre a rede de heteronomia que a compõe.

\title{
2.1. O conceito jurídico
}

O contrato como conceito jurídico pretende destacar a formalização pelo Direito de uma conduta humana autônoma, consciente e intencional na escolha do conteúdo eficacial da operação econômica que ele reveste. "Contrato é um conceito jurídico: uma construção da ciência jurídica elaborada (...) com o fim de dotar a linguagem jurídica de um termo capaz de resumir uma série de princípios e regras de direito." (ROPPO, 2009, p. 7).

Torna perceptível que o contrato como conceito jurídico é distinto da operação econômica, embora seja ela efetiva projeção do fenômeno negocial que pode ser imaginado num plano, no mínimo tridimensional, se considerados o conceito jurídico, a operação econômica e o direito dos contratos. A partir de sua realidade como estrutura da ciência do Direito, valida a existência da relação econômica. Aqui se imagina a construção jurídica, a partir, por exemplo, da verificação dos pressupostos para a sua existência. A identificação da presença de um agente que externaliza sua vontade de alguma maneira ou forma, seja ela 
escrita ou oral, por exemplo, em relação a determinado conteúdo jurídico, marcaria os indícios iniciais da existência de um contrato.

Além disso, para que se possibilite a concretização do contrato em sua acepção técnico-jurídica é necessária a identificação de um ajuste de condutas ou de um "acordo de coordenação de condutas." (ARAÚJO, 2007, p. 14). O ajuste de condutas costuma ser denominado de acordo de vontades, mas se aqui a opção se dá pela ênfase na natureza heterônoma da autonomia contratual, parece preferível evitar um idealismo da vontade. Afirmar a coordenação de condutas sugere uma descrição arguta do fenômeno contratual, em especial quando se investiga sua existência jurídica como forma de revestir uma operação econômica.

\subsection{O direito dos contratos}

A realidade constituída pelo contrato numa extensão macro e complexa é igualmente formada pelo direito dos contratos que pretende delinear um arcabouço de regras e princípios responsáveis pela estruturação do conceito jurídico e pela regulação da operação econômica. A expressão direito dos contratos pretende ilustrar não uma regulação passiva das transações negociais de modo a dar estrutura ao conceito jurídico, mas sim representa um conjunto de determinações e orientações efetivas urdidas conforme objetivos econômicos e políticos.

Se o direito dos contratos pretende dar nome a um universo complexo de regras, princípios e comandos legais de toda sorte sobre a realidade do contrato não se pode desconsiderar que tal universo seja conduzido por interesses de natureza econômica, até mesmo se considerada a realidade social e cultural do que se denomina mercado. $\mathrm{O}$ estudo do contrato desmembrado em três níveis, como sugere Enzo Roppo, reflete, no enfoque do direito dos contratos, a preocupação com as normas jurídicas reguladoras das relações negociais, mas principalmente uma preocupação em tonar claro que o universo do contrato sofre interferência das orientações políticas e econômicas que mobilizam várias reações de mercado.

Se o pressuposto neste trabalho tem sido o contrato como operação econômica representaria uma leitura pouco sistemática e minimamente consistente negar que a regras jurídicas que cuidarão desta realidade não são regras influenciadas pelo fato social que o mercado simboliza. Afirmar a existência do mercado significa reconhecer a existência de uma instituição entendida aqui como um conjunto de costumes e estruturas sociais estabelecidas em razão de um contexto social, antropológico, econômico e cultural. 
Deve ficar claro, de facto, que a disciplina legal dos contratos - longe de limitar-se a codificar regras impostas pela natureza ou ditadas pela razão (como afirmavam os seguidores do direito natural) - constitui, antes, uma intervenção positiva e deliberada do legislador (das forças políticas que exprimem o poder legislativo), destinada a satisfazer determinados interesses e a sacrificar outros, em conflito com estes, tentando dar às operações econômicas concretamente realizadas um arranjo e um processamento, conforme aos interesses que, de quando em quando, se querem tutelar. (ROPPO, 2009, p. 22)

As normas jurídicas que regulam o contrato devem assim ser articuladas da maneira mais sistemática possível, em termos de interpretação e aplicação. Significa dizer que princípios como a função social do contrato e a boa-fé devem considerar os conceitos de teoria geral do direito privado, bem como os direitos fundamentais previstos na Constituição da República, além de valores como a livre iniciativa e a dignidade humana, articulados à realidade da ordem econômica.

\subsection{A natureza heterônoma da autonomia contratual}

A descrição do que se chama de direito dos contratos torna-se legítima e necessária para se compreender o alcance das múltiplas "interferências" que o fenômeno contratual recebe ao longo de sua formação, execução e até mesmo após sua conclusão. Este "caminho" de percepção e compreensão da existência do contrato como conceito jurídico e moldado pelo direito dos contratos torna-se mais facilmente compreensível se imaginado como um processo obrigacional essencialmente discursivo.

Neste processo discursivo desenvolvem-se e se exercitam os poderes jurídicos autônomos de seus agentes, como sujeitos de direito capazes de escolhas sobre o conteúdo que comporá o vínculo negocial. O desenvolvimento da dialogia contratual, por meio da autonomia privada, revela a operação econômica em formação e trânsito, praticada igualmente entre elementos de heteronomia.

Parece recorrente no estudo da autonomia contratual relacioná-la à filosofia kantiana da autonomia ${ }^{10}$. Tradicionalmente o poder jurídico negocial dos contratos é denominado de autonomia da vontade e neste contexto sugere-se que a ideologia de Kant tenha influenciado a compreensão da autonomia como um poder jurídico negocial exercido de maneira absoluta. Afirma-se que a vontade, no universo dos contratos, estaria sendo percebida e endossada como uma espécie de dogma. A percepção da autonomia negocial era a de um poder jurídico

10 "Kant inicialmente acompanhou Crusius em sua concepção da estrutura do poder que nos permite ser autogovernado. Construiu a vontade como a exigência racional de consistência na ação. (...) Como podemos escolher, nunca temos de ceder a desejos que, embora certamente partam de nós mesmos, são causados em nós por nossos encontros com o mundo exterior. Kant combinou uma vontade crusiana com o tipo de liberdade da indiferença defendida por Malebranche, Locke e Clarke, para permitir não apenas a espontaneidade, mas também a autonomia." (SCHNEEWIND, 2001, p. 563).

Revista da Faculdade Mineira de Direito, v.12, n. 23, jan./jun. 2011 - ISSN 1808-9429. 
indiscutível ou incontestável, promovendo a exacerbação de princípios como a obrigatoriedade e relatividade dos efeitos do contrato. A reconstrução científico-jurídico do fenômeno da autonomia da vontade fez com que se afirmasse a existência de um poder jurídico negocial limitado por determinadas externalidades e perfeitamente passível de revisão de suas cláusulas em nome da justiça contratual. Sugeriu-se então a terminologia autonomia privada para a designação dessa faculdade negocial limitada por princípios como a boa-fé em sua acepção objetiva, a função social, assim como regras de revisão como a resolução por onerosidade excessiva.

A autonomia privada vem então tentando percorrer um caminho de renovação em relação à autonomia da vontade. Parece, entretanto, que alguns paradigmas relevantes ainda permanecem poucos destacados, apesar de poderem soar óbvios. Em primeiro lugar, a autonomia privada, sentida aqui no campo contratual, somente pode ser estudada e compreendida se percebida como um fenômeno precipuamente discursivo e relacional em que as categorias jurídicas vão sendo acertadas seja em que nível for. Diz-se isto, pois poderia haver oposição à percepção relacional quando da coordenação de condutas por meio de contratos chamados de adesão, cujo conteúdo é de pouca negociabilidade.

Em segundo lugar, a autonomia inclui em sua existência e exercício a manifestação da heteronomia. Seria como dizer que a autonomia possui uma natureza heterônoma que a compõe. $\mathrm{O}$ universo da autonomia representaria o exercício livre de determinadas faculdades entre uma rede de elementos heterônomos que articulam, moldam e compõem essa autonomia. Não parece possível que a autonomia tenha qualquer relevância se pensada além ou aquém do panorama da alteridade.

A autonomia sofre assim influências múltiplas na sua realização. Essas influências passam por preocupações e valores de ordem existencial, transitam pelas condutas juridicamente proibidas e obrigatórias que impõem determinados comportamentos, bem como passam pelas influências da racionalidade econômica. Os comportamentos de racionalidade econômica, é verdade, não deixam de sofrer resistência da racionalidade existencial, pois estão essencialmente articulados.

É real que os modelos econômicos pressupõem uma racionalidade um pouco mais objetiva do que aquela contida em tendências, inclinações e desejos de ordem meramente emocional. Porém, também estes modelos não estão imunes às transformações e alterações negociais que podem ocorrer, em completo desacordo com as previsões econômicas, dada a relevância dos elementos de heteronomia que movimentam a autonomia. Para que se cogite do contrato como operação econômica parece essencial compreender que o poder 
juridicamente reconhecido que o mobiliza tem em seu núcleo uma rede de singularidades heterônomas que o articula.

\section{A OPERAÇÃO ECONÔMICA}

Roppo afirmava que “(...) o contrato é a veste jurídico-formal de operações econômicas. Donde se conclui que onde não operação econômica, não pode também haver contrato." (ROPPO, 2009, p. 11). A operação econômica que o contrato "torna" jurídica evidencia-se de maneira macro pela evidente circulação de riquezas que a coordenação de condutas promovida por ele produz. Seja o contrato de natureza onerosa ou gratuita não há negligenciar que a relação jurídica possibilita o fluxo de bens e serviços oferecidos em troca de contraprestações equivalentes ou não. Igualmente um contrato como o aleatório promove a circulação de riquezas por meio de uma operação econômica que pode ser dita mais arriscada e pouco pré-estimada já que não se pode prever de antemão as prestações de cada agente. “(...) onde existe circulação de riqueza, actual ou potencial transferência de riqueza de um sujeito para outro (falando de riqueza não nos referimos só ao dinheiro e aos outros bens materiais, mas consideramos todas as utilidades susceptíveis de avaliação econômica).” (ROPPO, 2009, p. 13).

A operação econômica traz consigo a troca de utilidades feita de maneira onerosa ou não. As utilidades podem ser oferecidas por meio de prestações de bens e/ou serviços oferecidos e queridos no mercado, lócus de transações que lhe permitem um balizador de valores. Esse fato social mobilizador de permutas ou mesmo de um fluxo de utilidades já que nem todas implicarão em contraprestação se orientam por um conceito econômico denominado custo de transação.

\subsection{Contrato, custos de transação e mercado}

A circulação ou fluxo de bens valorados economicamente, bem como de serviços que são considerados importantes e requisitados socialmente parece ser o "objeto" do mercado. O mercado pode ser considerado, em primeiro lugar, como um fato social de costumes, hábitos econômicos de troca, organizadas por meio de determinados códigos e condutas. Ele possibilita de maneira relativamente consistente e coordenada esse fluxo de riquezas movimentado pelos contratos. "O mercado atende às trocas relacionais e, implicitamente, envolve a própria noção de comunidade. Sem mercado não há trocas, e, sem trocas, a economia não se desenvolve (...).” (PINHEIRO; SADDI, 2005, p. 15). O contrato aparece 
como relevante instrumento promotor de fluxo de riquezas desempenhado assim papal central na economia de mercado.

Igualmente, ou em acréscimo ao que foi dito sobre o mercado como fato social, podese acrescentar a natureza institucional do fenômeno que considera os costumes e as estruturas sociais regulados pelas leis. O mercado concentra o exercício das liberdades individuais ilustradas aqui pela autonomia/heteronomia contratual em que a noção de riqueza é definida pelos processos de interação (discursiva) entre os agentes. A relação entre mercado, direito e economia é nítida e não pode ser negligenciada no estudo dos contratos.

A escolha de mercado não é puramente racional, nem o resultado do processo científico de combinação de custo-benefício; ela leva em conta, muito mais, a interpretação de determinados significados, em esquema de incentivo /desincentivo. Assim é que o Direito, para Malloy, não cuida apenas de mediação do conflito em si - ele engloba também os valores dos processos de troca. (PINHEIRO; SADDI, 2005, p. 16)

A operação econômica que o contrato regula ilustra a coordenação de condutas valoradas economicamente em razão do fato mercado. O que se mobiliza na relação jurídicoeconômica do contrato se faz no mercado e para ele. E esse fluxo de utilidades é realizado em atenção a um sistema de cálculo de valores e prejuízos de maneira a movimentar as condutas contratuais. Cada decisão de conduta a ser realizada por meio do contrato passa por uma análise de vantagens e desvantagens, pois assim se detecta o que incentiva e ou deixa de incentivar determinadas prestações contratuais.

A teoria econômica dos custos de transação permite a inteligibilidade da relação jurídica contratual. Cada escolha por um tipo contratual pressupõe uma quantidade anterior de reflexões econômicas, morais, existenciais articuladas entre ônus e vantagens para cada um dos sujeitos envolvidos. Neste processo de deliberação inicia-se pela busca de informações sobre o parceiro contratual, sobre regras de preço, sobre a qualidade dos bens, sobre a presteza dos serviços. Em seguida, inicia-se o processo discursivo de negociação elegendo conteúdos jurídicos conforme as necessidades, desejos e objetivos dos seus autores.

No momento seguinte ocorreria a formação de contrato, que em alguns casos obedecerá a exigências jurídicas de formalização para sua efetiva validade. A atenção a forma representa também custos na operação econômica do contrato que devem ser antecipados e considerados na melhor decisão entre as partes. Além disso, quando se cogita dos custos de transação de contratos, indaga-se se naqueles de execução continuada, por exemplo, os parceiros no compromisso negocial o cumprirão na forma pactuada. Neste momento cogitase, essencialmente da proteção ao direito de propriedade e posse dos bens e sua adequada 
empregabilidade no contrato. Verifica-se o devido cumprimento das prestações em atenção aos benefícios e custos de cada parte.

Por fim, na avaliação de custos de transação pode-se afirmar que são cogitadas as consequências jurídico-econômicas diante do inadequado cumprimento das prestações contratuais. A cobrança de indenização por prejuízos às partes é também antecipada no processo discursivo de negociação contratual validando sua existência como operação econômica que é. "Os custos de transação são o principal elemento motivador da Teoria NeoInstitucionalista, de acordo com a qual o principal papel das instituições econômicas é reduzir o valor desses custos" (PINHEIRO; SADDI, 2005, p. 62), e, por certo, o contrato é uma destas formas de redução.

"Foi Ronald Coase quem primeiro chamou a atenção para a importância dos custos envolvidos na iteração humana. Em especial, em artigo publicado em 1937, ele analisou como tais custos influíam na divisão entre transações realizadas dentro da empresa." (PINHEIRO; SADDI, 2005, p. 62) A noção de empresa aqui empregada vai ao encontro da definição hoje feita pelo Código Civil brasileiro que a recebe como atividade. Todavia, o conceito estabelecido pelo código ainda não levava em conta a noção de mercado e de uma realidade econômica inerente ao universo do Direito. Assim, empresa além de ser compreendida como atividade exercida pela pessoa jurídica ou pela pessoa natural (empresário individual) deve ser imaginada como uma grande rede de relações contratuais simultâneas.

\subsection{Contrato e empresa}

Embora se reconheça o emprego eventual da noção de empresa como sujeito de direito e talvez como forma de designar a sociedade que exerce atividade empresária, o que se percebe da definição legal e de toda a teoria jurídica sobre o tema é o efetivo emprego da expressão empresa como atividade. Uma realidade de atos articulados entre si de forma interdependente permite a visualização da atividade dita empresa. Além disso, essa atividade não pode ser exclusivamente científica ou literária. E o desenvolvimento desta atividade se dá seja pela constituição de pessoa jurídica específica como a sociedade, seja pela pessoa natural denominado empresário.

A empresa como atividade delineia um universo complexo de atividades que serão juridicamente reguladas, bem como será economicamente consideradas. Isto significa dizer que a toda a teoria dos custos de transação será operada quando se pressupõe a empresa. E a representação jurídica do comportamento racional em relação a estes custos será feita por meio do contrato.

Revista da Faculdade Mineira de Direito, v.12, n. 23, jan./jun. 2011 - ISSN 1808-9429. 
O fenômeno negocial do contrato representa uma maneira jurídica e economicamente válida e legítima de se articular interesses e necessidades, permitindo seja feita uma contabilidade sobre custos e benefícios. O exercício da atividade denominada empresa se torna então menos oneroso se desempenhado por meio de contratos adequadamente contabilizados e antecipados.

A teoria de Ronaldo Coase aqui mencionada afirma que a empresa não seria nada mais que um panorama de contratos articulados sempre em atenção a se reduzir os custos de transação. Cada vínculo jurídico desenvolvido pela atividade empresária se justificaria na forma de um contrato redutor de custos. Assim, supondo uma atividade empresária de locação de veículos, cada contrato de aluguel com o consumidor seria antecipado como um pequeno universo de uma realidade econômica. Além disso, os custos de transação também seriam considerados no momento de se decidir pela contratação de uma oficina mecânica de manutenção permanente dos veículos, do pagamento apenas por conserto ou na contratação, com vínculo trabalhista e representado outro contrato de mecânicos profissionais. Aqui são sugeridos aspectos mínimos como exemplo do "feixe" de contratos por meio do qual se desenvolve a atividade empresária já que esta também considera e deve considerar o fato institucional do mercado.

$\mathrm{Na}$ definição do conceito jurídico de empresa encontram-se elementos como a organização e os fatores de produção, que articulados pressupõem uma redução de contabilidade. O contrato permite que a troca de utilidades feita por meio da atividade empresária articule de forma eficiente os custos de transação. A adequada articulação dos fatores de produção na atividade dita empresária se dá pela eleição de condutas contratuais eficientes. "Se o contrato adquire relevância cada vez maior com o progressivo afirmar-se do primado da iniciativa da empresa relativamente ao exercício do direito de propriedade, é também porque este constitui instrumento indispensável ao desenvolvimento profícuo e eficaz de toda atividade econômica organizada." (ROPPO, 2009, p. 67).

\section{CONSIDERAÇÕES FINAIS}

O contrato como operação econômica amplia seu universo jurídico de aplicação, pois transcende a relação tradicional com a propriedade para encontrar-se também no universo negocial da atividade empresária. A transferência de riquezas feita entre os agentes que participam do contrato apresenta elementos ou natureza efetiva de um "jogo" econômico. Seja como troca nas relações contratuais onerosas como a compra e venda, a locação e a prestação 
de serviços, seja em relações contratuais em que não existe a troca, pois são gratuitas, operase a circulação de riquezas.

A concepção de riqueza na relação jurídica do contrato deve ser entendida em sentido amplo, pois a contabilização dos custos de transação percorre tanto elementos de natureza essencialmente patrimonial como aqueles de natureza extrapatrimonial. Por mais que se diga que determinadas decisões de natureza existencial sejam realizadas em nome do altruísmo, o exercício da autonomia negocial se dá, também, em cogitação ao que se perde e o que se ganha.

A racionalidade econômica é operada em situações em que tradicionalmente se verifica a noção da riqueza, mas também se desenvolve em contexto que a avaliação econômica direta, imediata ou precisa não pode ser feita. Porém, isso não retira a natureza econômica das condutas coordenadas entre os sujeitos de direito, já que toda uma racionalidade de pensamentos de perdas e ganhos é mobilizada em qualquer relação contratual.

A eficiência do contrato é então medida conforme a melhor ou pior adequação das condutas contratuais. A "funcionabilidade" (ROPPO, 2009, p. 221) seria verificada se todas aquelas fases previstas nos custos de transação se desenvolvesse mais ou menos próximas das antecipações das partes. Aquilo que é imprevisível e arriscado é nuclear na operação econômica e no conceito jurídico de contrato que a reveste, embora o cálculo de custos de benefícios seja efeito exatamente para minimizar o imponderável. Uma reconstrução crítica do contrato como fenômeno jurídico deve ser feita em atualização concomitante com a noção heterônoma da autonomia contratual, bem como pela percepção da natureza substancialmente econômica da operação.

\begin{abstract}
The present paper is focused on the relationship between the legal reality represented by the contract and the economic operation which it legitimizes. The purpose here is to make more consistent the study of the contract through the recognition and understanding of the socioeconomic fact which gives it form.
\end{abstract}

Keywords: contract, autonomy, law, economy.

\title{
REFERÊNCIAS
}

ARAÚJO, Fernando. Teoria econômica do contrato. Coimbra: Almedina, 2007. 
BETTI, Emílio. Teoria geral do negócio jurídico. Tradução de Ricardo Rodrigues Gama. Campinas: LZN, 2003.

BRANCO, Gerson Luiz Carlos. Função social dos contratos: interpretação à luz do código civil. São Paulo: Saraiva, 2009.

COASE, Ronald H. The new institutional economics. Disponível em: $<$ http:/links.jstor.org/sici=sici=002282\%199805\%2988\%3A2\%3C72\%3ATNIE\%3E2.0.CO\% 3B2-M>. Acesso em: 28 jul. 2008.

COASE, Ronald H. The firm, the market and the law. Chicago: London: Chicago University, 1988 apud ROBBINS, Lionel. An essay on the natural and significance of economic science. 2. ed., London: Macmillan \& Co., 1935, p. 16.

COASE, Ronald $\mathrm{H}$. The problem of social cost. Journal of Law and Economics, Chicago, v. 3, n. 1 , p. $1-44,1960$.

COOTER, Robert; ULEN Thomas. Law and economics. 5.ed. Califórnia: Addison-Wesley: Longman, 2008.

FERES, Marcos Vinício Chein; DIAS, João Paulo Torres. Teoria geral dos contratos relacionais. Revista de Direito Privado, São Paulo, n. 30, p. 171-182, 2007.

FRANCO, Denis. O princípio da autonomia: da invenção à reconstrução. In MORAES, Maria Celina Bodin de (coord.). Princípios do direito civil contemporâneo. Rio de Janeiro: Renovar, 2006, p. 135-162.

GAROUPA, Nuno. Análise económica do direito. Cadernos de Ciência de Legislação, Coimbra, n 32, p. 23-38, dez. 2002.

LISBOA, Roberto Senise. Contratos difusos e coletivos. São Paulo: Revista dos Tribunais, 2007.

LORENZETTI, Ricardo Luis. Tratado de los contratos: parte general. Buenos Aires: Rubinzal-Culzoni, 2004.

MARTINS-COSTA, Judith. Reflexões sobre o princípio da função social dos contratos. Revista Direito GV, São Paulo, n. 1, p.41-66, jan./jun., 2005.

MELLO, Marcos Bernardes de. Teoria do fato jurídico: plano da existência. São Paulo: Saraiva, 2003.

NEGREIROS, Teresa. Teoria do contrato: novos paradigmas. 2.ed. Rio de Janeiro: Renovar, 2006.

NUSDEO, Fábio. Curso de economia: introdução ao Direito Econômico. São Paulo: RT, 2007.

PIMENTA, Eduardo Goulart. Direito, economia e relações patrimoniais privadas. Revista de Informação Legislativa. Brasília, v. 43, n. 170, p.159-173, abr./jun. 2006 b. 
PINHEIRO, Armando Castelar; SADDI, Jairo. Direito, economia e mercados. São Paulo: Elsevier Campus, 2005.

POSNER, Richard A. El análisis económico del derecho. Tradução de Eduardo L. Suárez. México: Fondo de Cultura Económica, 2007b.

POSNER, Richard A. Maximización de la riqueza y Tort Law: una investigación filosófica. Disponível em: <http://www.eumed.net/cursecon/textos/posner-tort.pdf.>Acesso em: 25 jul. 2008.

PRATA, Ana. A tutela constitucional da autonomia privada. Coimbra: Almedina, 1982.

REZZÓNICO, Juan Carlos. Princípios fundamentales de los contratos. Buenos Aires: Astrea, 1999.

ROPPO, Enzo. O contrato. Coimbra: Almedina, 1988.

ROPPO, Vicenzo. Il contratto. Milano: Giuffrè, 2001.

SALAMA, Bruno Meyerhof. O que é pesquisa em direito e economia Revista Direito GV, São Paulo, n. 2, v.5, p. 5-58, mar. 2008.

SAMPAIO JÚNIOR, Rodolpho Barreto. Da liberdade ao controle: os riscos do novo Direito Civil brasileiro. 2007. 214f. Tese (Doutorado em Direito) - Universidade Federal de Minas Gerais, Belo Horizonte.

SCHNEEWIND, J.B. A invenção da autonomia. São Leopoldo: Unisinos, 2001.

STZAJN, Rachel. Notas de Análise Econômica: contratos e responsabilidade civil. Revista de Direito Mercantil, São Paulo, n. 111, p.9-29, 1998.

STZAJN, Rachel. Teoria jurídica da empresa. São Paulo: Atlas, 2004.

SZTAJN, Rachel. Externalidades e custo de transação: a redistribuição de direitos no novo código civil. Revista de Direito Privado, São Paulo, n. 24, p. 250-276, 2005 a.

TIMM, Luciano Benetti. Ainda sobre a função social do direito contratual no Código Civil brasileiro. In TIMM, Luciano Benetti (org.). Direito e Economia. Porto Alegre: Livraria do Advogado, 2008, p. 63-96.

WALD, Arnold. O interesse social no direito privado. In FACHIN, Luiz Edson; TEPEDINO, Gustavo (coord.). O Direito e o tempo: embates jurídicos e utopias contemporâneas. Rio de Janeiro: Renovar, 2008, p. 77-102 